\title{
Influence of Correctional Facility Environment on Juvenile Recidivism
}

\author{
Sebastian Okello Wang'ombe \\ Kibabii University, P.o Box 1699 - 50200 , KENYA
}

\begin{abstract}
Juvenile crime and the problem of juvenile recidivism are on the increase in Kenya. Most of adult offenders are also noted to have begun their criminal behaviours in their juvenile years, making the need to contain criminality to be so glaring at the moment. The rate at which juveniles are recidivating in Kenya is alarming while the root causes are yet to be determined. The Government of Kenya introduced rehabilitation institutions to deal with rehabilitation of child offenders and prevent them from recidivating. While statistics indicate juvenile crime and recidivism to be on the increase, studies on the phenomenon of recidivism among juveniles in correctional institutions in Kenya are scanty. The purpose of this study was to establish the influence of socio-demographic characteristics on recidivism among juveniles in rehabilitation institutions in Kiambu and Kirinyaga counties of Kenya. The study objectivewas to establish the influence of correctional facility environment on juvenile recidivism. The study was based on Robert Merton's 1938 strain theory. The study adopted a descriptive survey research design. The target population for the study was 333 juvenile recidivists and 60 correctional staff in Wamumu and Kirigiti rehabilitation schools in Kirinyaga and Kiambu counties of Kenya respectively. The data for the study was collected by use of questionnaires, Focused Group Discussion, in-depth interview schedules and document analysis and analyzed using descriptive statistics. Pilot study was carried out to ascertain the reliability of the instruments by use of test retest technique at 0.8 reliability index, while experts assisted in determining the content validity of the instruments. The study suggested a correlational study to determine if a statistical relationship exists between Correctional Facility Environment and Juvenile Recidivism.
\end{abstract}

Keywords: Correctional Facility, Environment, Juvenile Recidivism

DOI: $10.7176 / J L P G / 87-01$

Publication date:July $31^{\text {st }} 2019$

\section{Introduction}

Owing to the increasingly growing problem of juvenile crime and recidivism; and the recognition that adult criminals begin their criminal careers in their juvenile years, the need to contain juvenile offending has never before been so glaring. Delinquency of young offenders can be predicted, prevented and treated. But the methods most often used to predict, prevent and treat juvenile delinquency typically derive from stereotypical conceptions, which often yield very low accuracy levels because of lack of empirical researches on the subject (Mbuba, 2004). A study on 20-year trends in juvenile detentions, correctional and shelter facilities in the United States showed that "there were more juveniles... in more crowded, secure, and costly juvenile correctional facilities in 1995 than there were in the preceding years" (Smith, 1998:539).

Furthermore, violent crimes are being committed by younger and younger persons and are even increasing among middle-class youth in suburban neighborhoods and communities in United States (Durant, 1999:268). In 2000 the number of arrests for persons under 18 years in the United States stood at a staggering 1,560,289. Out of these, those charged with violent crimes such as murder, non-negligent manslaughter, forcible rape, robbery, and aggravated assault were 65,910 while those charged with property crimes, including, burglary, larceny-theft, motor vehicle theft, and arson, were 345,731 ( Pastore \& Maguire, 2002:352).

According to Akers (1985), criminal acts and the resultant formal sanctions can give the affected individuals the greater exposure to and affinity for other individuals who constantly violate the law and this patterning of reinforcement leads to elevated participation in further criminal behavior. It has been argued that whether or no prior offense will determine reoffending largely depends on the number and severity of previous offenses, often in the region of five or more times (Snyder, 1998). The relationship between drug use and delinquent behavior has attracted a lot of concern in the last few decades. Although in the public mind the relationship between drugs and crime is often seen as fairly straightforward, with drug use being viewed as directly causing criminal behavior, critical analysis has found the relationship far more complex (McBride \& McCoy, 1997; Parker \& Auerhahn, 1998; Day et al., 2003). A study of alcohol, drugs, and violence showed no significant evidence to suggest that drug use is associated with violence but demonstrated substantial evidence to suggest that alcohol use is significantly associated with violence of all kinds (Parker \& Auerhahn, 1998).

However, other studies have found an important association between use of drugs and the rate of recidivism (Grenier and Roundtree, 1987; Haapanen, 1990; Howell, 1995). Nevertheless, although other studies have attempted to establish the relationship between drug use and offending, they have only showed that offenders are, in general, heavy substance users while heavy substance users are disproportionately likely to engage in criminal 
activity. This, according to McMurran (1996), does not confirm drug use as an important predictor of recidivism as the antipodal relationship is also possible. In spite of these findings, other recent studies has found positive associations between use of drugs/substance abuse including alcohol and reoffending, and have thus belied this view, with a conclusion that use of drugs/substance abuse increases the likelihood of recidivating for young offenders (Loza, et al., 2004; McCoy, et al. 2004).

Family stability, often defined from the point of view of whether or not both parents are living together with their siblings, is the single most important factor in ensuring that a child is properly assimilated into the mainstream of society. The influence of the family in reducing or encouraging recidivism stems from the notion of social control, where it is believed that parental influence is capable of counteracting negative swings in adolescents and forms a potential barrier to delinquent behavior (Warr, 1993). Warr also argues that an attachment to parents helps inhibit the initial formation of delinquent friendships, which itself helps interrupt the cycle of negative peer influence and delinquent behaviour. A large body of research has successively and steadily linked peer influence to patterned delinquent behavior, with peer pressure forming a central explanation of not only the first involvement in delinquency, but also the repetitive pattern that typifies recidivism (Loeber \& Loeber, 1987; Warr \& Stanford, 1991; Warr, 1993; Thornberry, et al., 1995; Matsueda \& Anderson, 1998; Benda, 2001; National Research Council \& Institute on Medicine, 2001). Indeed, delinquent peers and delinquent behavior have been found to be reciprocally related; delinquent peer association's foster future delinquency and delinquency increases the likelihood of associating with delinquent peers (Matsueda \& Anderson, 1998:269). In a study on the influence of delinquent peers, Warr and Stafford (1991) found that the attitudes of adolescents are influenced by the attitudes and behavior of their peers and those attitudes in turn affect delinquency. The consequence of peer influence on recidivism has been intertwined with the effect or criminal history (Sutherland and Cressey, 1947; Akers, 1985). Individuals who have a positive definition towards crime have a higher affinity for one another and this reinforces their creed thereby leading to further crime. However, the relationship between peer influence and delinquency has long been questioned, with Glueck \& Glueck (1950:164) proposing that delinquency may not be caused by the transmission of definitions favorable to violation of law through associating with other delinquents, but it may be that "birds of a feather flock together".

Moles and Rowland (1998) noted that the major causes of most juveniles not reforming in USA include: cramped cells, sleeping on cemented floors, clogged toilets, no medical facilities and attention, lack of recreational services, and inability to protect themselves from other offenders. That social life in juvenile correctional facility is unimaginable without recreational programs. Juvenile recidivists need recreation to interrupt a dull routine. Sports take steam out of the inmates and they provide entertainment. Moreover, they found out that most juvenile correctional facilities are old and lack most of these facilities. In Netherlands, treatment of juvenile recidivists a part from focusing on case intervention, it also emphasizes follow up and after care services which has been proved to play an important part in rehabilitation process. After care service provides continuous observational and supervisory treatment of the subjects up to over six months after reintegration (Cottle 2001: 344-350). World Organization against Torture (2001) in their annual report to United Nations Convention on the Rights of the Child noted that in Mexico's juvenile correctional facilities, many juvenile recidivists come with them a lot of illness including mental and psychological illnesses, however, there has never been evidence that these children on admission are not screened for any ailment whether skin, respiratory, psychological or mental illness. Most of these ailments are detected late and not treated.

Most of the sick juvenile recidivists are taken for medical attention very late making their treatment taking very long or finishing their committal terms before full recovery. Most illness that requires isolation are not attended to as required due to lack of isolation facilities. The management of rehabilitation schools must ensure that children in their institutions have good health both physically and mentally. According to Malesi (2006: 5657), in South Africa, programs that target employment of juvenile delinquents are emphasized. They use cost effective interventions which are skill based and which also include a cognitive component in order to address the values, attitudes and beliefs that support offending behaviour. The treatment programs in South Africa are based on the principles of Vennard (1997), which are intended to improve effectiveness of programs for offenders. These include: Targeting dynamic risk factors, risk classification, community based intervention programs, program responsiveness treatment modality and program integrity.

In Uganda according to Tanasha (2008:123-129) community based treatment of juvenile recidivists has been encouraged by the government due to increase to number of juvenile recidivists caused by real economic need due to death of their parents due to HIV and AIDS scourge. Grandparents, aunts and uncles play an important part in rehabilitating delinquent juveniles by taking them back to school or by offering them relevant training. She also noted that the few rehabilitation centers in Uganda are congested and lack adequate facilities and programmes to effectively deal with delinquency in offenders. Consequently, the necessity to contain young offenders before they become ensnared in adult criminal occupations presents a societal concern that has never before been so glaring in Kenya. Comparable to Kenyan statistics where 35 percent of those released in 
1999/2000 had reoffended after one year afterwards (Lavera 2002) while 15\% reoffended before expiry of two years from release time. During 2003, 2007 and 2011 period, 22 percent, 28 percent and 51 percent of the boys and 14 percent, 22 percent and 29 percent of the girls had reoffended within the first year of release, the causes of this high recidivism rates need to be established (DCS, 2012) Kinyua (2010) found out that Central Kenya region especially Kiambu and Kirinyaga counties had recorded significant increase in cases of children offending and reoffending between the years of 2008-2012. The free flow of money generated from criminal and juvenile gangs encourages many young men and women to abandon school and engage in criminal activities. Kirinyaga, Muranga and Kiambu districts of Kenya had the highest number of young people engaging in drug and alcohol abuse in the Kenya.

\section{Statement of the Problem}

Juvenile crime and recidivism is a new social problem facing many countries of the world including Kenya. In the United States of America, between 2000 and 2002, about 2, 345, 653 juvenile recidivists had been arrested for more than once for engaging in criminal activities. In Norway during the same period more than 45 percent of juveniles in juvenile correctional institutions were recidivists. In South Africa, the problem was even more critical with more than 47 percent of juveniles reoffending a year after release from rehabilitation institutions (Pastore \&Maguire 2000:343). Lavera (2002) found out that over 35 percent of child offenders in Kenya's rehabilitation schools had reoffended just within one year after reintegration during 1999/2000 fiscal year. According to DCS (2012), out of the total number of child offenders who underwent treatment in rehabilitation schools in $2003,22 \%$ of boys and $14 \%$ of girls re-offended. In the year $2007,28 \%$ of boys, and $22 \%$ of girls reoffended. In 2011 , about $51 \%$ of boys and 29 percent of girls in correctional facilities had reoffended within the first year of reintegration. The high rate of juvenile recidivism in the Kenya have resulted into family conflicts, property damage and loss, lost investment opportunities, physical injury and loss of life and; psychological and emotional wounds resulting into underdevelopment of the country and long period of suffering on the part of offender and victim. Children have continued to commit heinous criminal acts such as murder, rape, arson, defilement and trafficking in drugs. Reduced juvenile recidivism would contribute to a safe country which will result into more investments resulting into more employment opportunities, stable families and therefore economically and socially stable citizens. It was in view of this that the researcher set out to investigate the influence of correctional facility environment on juvenile recidivism in Kiambu and Kirinyaga Counties of Kenya.

\section{Research Objectives}

Examine the influence of correctional facility environment on juvenile recidivism

\section{Research Questions}

How does correctional facility environment influence juvenile recidivism?

\section{Literature Review}

Rehabilitation of offenders in residential juvenile correctional facilities to a large extend depend on the way administrative concerns are managed. This is because they deal with disadvantaged children who although they are in conflict with the law, require same treatment like any other children. Juvenile correctional institutions are supposed to have members of staff who are suitably qualified, competent and with relevant experience. The employment of members of staff should be guided by the mission and policy statement of the institution, the health and welfare of the children, population of offenders; and specific risks and needs of the children accommodated in the institutions (Corrado, 2003). Malesi (2004) revealed that unlike prison staff that continuously undergoes refresher courses in South Africa, staff in juvenile correctional institutions does not. She further, noted that most workers in juvenile correctional institutions come from the surrounding areas and who continue working in those institutions because they are the only available jobs available for them as per their basic education. Furthermore, she noted that because of poor policies, these workers have stayed in the same institutions for so long that they are always against any new positive changes introduced to improve the programs in these institutions.

According to Grobbel (2002), there is an urgent need for staff in juvenile correctional facilities to undergo capacity building to understand new challenges in the rehabilitation of juvenile recidivists and to boost quality in implementation. The employment of staff in juvenile correctional facilities should be based on the risks and needs of the offenders. Marvin (1988:68-69) indicated that the major hindrance to juvenile rehabilitation programs is congestion of offenders in rehabilitation centers. Despite ever increasing number of population in rehabilitation centers the state budget has remained constant over a long period of time. This overcrowding has put a lot of pressure on a few available rehabilitation programs and resources available thus resulting into release to the society of unreformed subjects. Moles et al (1998:30-31) revealed that committing of juvenile delinquents 
in rehabilitation centers for long periods of time, results in the formation of social entities. These entities have their own traditions, norms, language, and roles. The subject's constitute a unique social group. They live together, but not voluntarily. They live in extremely close quarters, often sharing all the space. It should also ensure that the people who are mentioned in the complaint do not participate in deciding what should happen. However, the authority may allow for this at the proper time. The procedure should also indicate how complaints against those in authority should be done. Juvenile recidivists' communication with the parents and other siblings assists him/her to work on his/her rehabilitation programs as a way of expecting to be released early and return to the family. This communication also assists the child to be less violent, hostile and stop trying to escape. Wanyoike (1989) revealed that premises of the correctional institution should be in a location and of a design and layout that enables it to meet its objectives as laid out in its mission and policy statement. The premises should be well lit, ventilated and adequately heated or cooled.

It should also be secure, suitably furnished and equipped. It must be kept clean and decorated in a child friendly manner. The premises must always be well maintained and kept in good repair. It should also be suitable for any children with special needs staying in the institution. The environment around the premises should always be kept clean and proper arrangements made for the disposal of general and any clinical waste. With consideration of the children's ages, sexes, special needs and their number, the institution should have suitable and adequate number of toilets and bathrooms with enough washbasins and a constant supply of clean water. These facilities should offer sufficient privacy to the children.

According to Murambi (2009:16-24) the following disciplinary measures should not be used on offenders as they lead to hardening of criminality in offenders: Any form of corporal punishment; denying children food or drink (water); restricting a child from being in contact with or visited by parents, relatives or friends except from when such restrictions are imposed by a court; making children wear inappropriate clothes; denying children medical attention; intentionally denying a child of sleep; ask the child to pay money ; intimately, physically examining the body of a child; withholding the aids or equipment needed by a child with disability; asking children to punish each other or punishing a group of children for the mistakes of one child and any measure which is degrading, dehumanizing or cruel. According to Directorate of Personnel Management (2004) annual report on operations and staffing of the Department of Children Services revealed that training workshops in rehabilitation schools had closed down due to lack of personnel and equipment. The funds that were being used to buy such equipment had been struck out of budget schedules. Teachers Service Commission also has withdrawn P1 teachers it had seconded to these schools due to acute shortage of teachers in her schools.

The study found a lot of inconsistencies on which factor in correctional environment had the highest influence on recidivism among child offenders passing through them. Although Murambi (2009) emphasized mode of rehabilitation used, Wanyoike (1998) had indicated that lack of child friendly environment was the main cause of recidivism among child offenders. In contrast, Human Rights Watch (1997) indicated that it was lack of complaints procedure through which child offenders can channel their suggestions and complaints. Marvin (1988) in his reported indicated that congestion was the main correctional facility factor contributing to reoffending among child offenders; Moles (2004) and Grobbel (2002) indicated that lack of adequate skills by correctional officers was the main factor in the correctional facility contributing to the higher rates of recidivism.

It was against this backdrop that the current study sought to examine the factors in correctional facility environment in order to come up with a factor that has the greatest contribution on recidivism of child offenders passing through correction facilities in Kiambu and Kirinyaga counties, Kenya and provide more literature to future studies on the phenomenon of juvenile recidivism.

\section{Research Methodology}

The study employed a descriptive survey research design. In employing a descriptive research design, the researcher sought to examine the influence of correctional facility environment on juvenile recidivism. The decision to adopt a descriptive research design was guided by the observation by Mugenda (2008) that descriptive research designs are commonly used when examining social phenomena that exist in communities. Mugenda noted descriptive studies because of their exploratory nature to be easier and simpler to conduct, yet quite important for providing foundation upon which correlational and experimental studies emerge. Study area for this research was Kiambu County (Kirigiti Rehabilitation School) and Kirinyaga County (Wamumu Rehabilitation School).

The target population refers to an entire group of individuals, events or objects having common observable characteristics from which a sample which is a smaller group is obtained (Ahuja, 2001: Mugenda \& Mugenda, 1999). The target population comprised of 333 repeat offenders and 60 correctional officers in two rehabilitation schools. Juvenile recidivists are ex-child offenders who have tendency to revert to criminal behavior soon after their release from juvenile correctional facility. Random sampling table was used to identify the one hundred juvenile recidivists from different strata of 333 repeat juvenile recidivists as respondents. Furthermore, simple random sampling table was used to select 20 correctional officers from a sample size of 60 correctional officers 
in the selected rehabilitation schools. Respondents were proportionately sampled across the correctional facilities. The data obtained from the field was organized on the basis of source and serial numbers of the data pieces. The data was then inspected for completeness and then edited or errors. Before coding the data, all the data pieces from all instruments were identified and a list of all of them made.. After entering the data onto a display sheet, descriptive including means, percentages and standard deviations were computed. Qualitative data was received in verbatim, transcribed, organized, reported and recorded in themes and sub themes. All objectives were analyzed by use of descriptive statistics such as percentages. Mean, mode and standard deviation.

\section{Findings}

\section{Juvenile Recidivist's Initial Correctional Facility}

The study further sought to establish the first correctional facility that respondents were committed after initial committal. Out of 100 respondents in the study $98 \%$ indicated rehabilitation school as their initial committal facility, $2 \%$ were committed in boarstal institutions while $4 \%$ were put under supervision of responsible adult person. This finding was interpreted to mean that juvenile recidivists from rehabilitation schools are reoffending more than those from other intervention modalities. The finding that rehabilitation schools are producing more recidivists than other intervention modalities was agreed by findings by Nyamato (2006) that more recidivists in boarstal institutions were previously committed in rehabilitation schools. The study also sought to find out from respondents whether life in their initial correctional facility was appealing to them. Out of 100 respondents in the study, $77(77 \%)$ indicated that life in their initial facility was not appealing, while $23(23 \%)$ indicated that life in their prior facility was appealing.

Out of the $23 \%$ whose life in initial facility was appealing, $16(69.57 \%)$ indicated that it was because they were sure of getting food, $4(17.39 \%)$ was because they got training opportunity while 3 (13.04) of the respondents indicated that availability of good friends. Out of 77 respondents who indicated that life in their prior facility was not appealing, 28 (36.36\%) found life unappealing because of use of corporal punishment, 8 $(10.39 \%)$ due to lack of formal schooling, $16(20.78 \%)$ was because of lack of relevant training programmes, 15 $(19.48 \%)$ because of lack of spiritual counseling. The findings were interpreted to mean that use of corporal punishment in the correctional facilities was the main factor that made life unappealing to majority of respondents. The Finding that majority of respondents in the study found life in their initial facilities appealing because of availability of food collaborated by finding of Mukozi (2010) that offenders in juvenile rehabilitation centers in Kampala, Uganda found life appealing because they were sure of getting regular three meals per day. However, the finding that majority of respondents found life unappealing because of use of corporal punishment disagreed by finding by Mbuba (2004) that $67 \%$ of juvenile recidivists in the state of Louisiana, United States found life unappealing because of lack of freedom.

Table 3: Provision of Spiritual and Counseling Services

\begin{tabular}{lcccc}
\hline Psychosocial support Services & \multicolumn{2}{c}{ YES } & NO \\
\cline { 2 - 5 } & $\mathbf{( F )}$ & $\mathbf{( \% )}$ & (F) & (\%) \\
\hline & & & & 85 \\
Spiritual guidance & 15 & 15 & 85 & 85 \\
Counseling Services & 43 & 43 & 57 & 57 \\
\hline
\end{tabular}

Majority ( 85 or $85 \%$ ) of the respondents indicated that they never received spiritual guidance when in need as shown in table 4.25. Furthermore, the study established that, out of 100 respondents 57 (57\%) indicated that they never accessed counseling services. This was interpreted to mean that highest percentage of respondents in the study did not access psycho social support especially spiritual guidance and counseling services. This also meant that those respondents who had traumatic experiences, spiritual needs and negative experiences never got assistance despite a lot of literature reviewed indicating that many children come with them many psychological needs a rising from their families or previous institutions that need immediate attention before commencement of other rehabilitation processes.

Findings by Morrison (2010) that majority of the respondents in the state of Nevada, United States who were undergoing rehabilitation for drug and alcohol addiction accessed psychosocial support especially counseling disagreed with findings of the current study where majority of the respondents were not able to access psychosocial support.

\section{Negative Behaviours Experienced by Juvenile Recidivists}

The study further sought to establish if respondents came into contact with experience in correctional facility that impacted negatively on their behaviour. All $100(100 \%)$ of the respondents indicated that they had come in contact with negative experience while in juvenile justice system at one time or another. This was interpreted to mean that some of the criminal behaviours exhibited by the respondents were acquired through experience in the juvenile justice system. out of 100 respondents who had acquired negative experience, 45 (45\%) indicated that experience of homosexuality/lesbianism impacted more negatively on them than any other behaviour while 
sexual molestation of offenders by staff at $10(10 \%)$ representation was indicated by respondents as the experience with least negative impact. and abuse by correctional staff at $15(15 \%)$. This finding that experience of homosexuality/lesbianism was the behaviour that had most negative impact on respondents was contradicted by findings by Malesi (2006) who found out that drug use among juvenile in South Africa had most negative impact on that other offenders.

\section{Frequency of visit of Respondents by their Parents/Guardians}

The study sought to establish how regularly respondents were visited by their parents and guardians while in correction facility.

Table 4: Frequency of Visits by Parents/Guardians

\begin{tabular}{lcc}
\hline Regularly visited by Parent/Guardian & $($ F) & $(\%)$ \\
\hline YES & 5 & 5 \\
NO & 95 & 95 \\
\hline Total & $\mathbf{1 0 0}$ & $\mathbf{1 0 0}$ \\
\hline
\end{tabular}

As presented in table 4.26, 5 (5\%) of respondents indicated that they were visited regularly by their parents/guardians while in correctional facility. Majority 95 (95\%) of respondents indicated that they had never been visited by their parents or guardians while in correctional facility. This was interpreted to mean that immediately children are committed in correctional facility they were neglected by close family members. Findings by Department of Children Services (2007) noted that $98 \%$ of the juvenile recidivists in rehabilitation schools are not visited by their parents and guardians therefore agreeing with finding of current study that majority of respondents were not visited by their parents or guardians.

\section{Juvenile Recidivists Interaction with Hard Core Criminals}

The study sought to establish whether respondents at any stage in juvenile justice system interacted with hard core offenders. Out of 100 respondents sampled for the study $77(77 \%)$ indicated that they had interacted with hardcore offender while 23 (23\%) never came into contact with hardcore offenders. This was interpreted to mean that, hardening of respondents into criminality was due to their interaction with hard core offenders. This finding that majority of respondents had interacted with hardcore offenders was found to be in line with findings by Peterson (2009) that $69 \%$ of juvenile recidivists in Colombia maximum rehabilitation centers had interacted with hard core offenders during their time in the juvenile justice system. The study further sought to establish the place where the respondents interacted with hard core offenders. Out of 77 respondents who had interacted with hard core offenders, majority 48 (59.74\%) of them indicated that they interacted with hardcore offenders during their remand period at children remand homes; 15 (19.48\%) from adult remand homes; 2 (2.60\%) from boarstal institutions, $1(1.30 \%)$ from adult prisons and $13(16.88 \%)$ from rehabilitation schools. These findings can be interpreted to mean that some of the respondents were remanded with adult remandees in adult remand in prisons, while others were even committed to prison term without due regard that they were children. This interaction with hardcore offenders exposed respondents to various modus operandi of different crimes which likely led to their hardening in delinquency.

\section{Good thing about Initial Correctional Facility}

The study sought to establish from juvenile recidivists whether there was anything good they remember about initial correctional facility they were committed in. Out of 100 respondents sampled in the study, 75 (75\%) indicated that they had good friends whom they miss, $10(10 \%)$ indicated that initial correctional facility provided them with food, while $7(7 \%)$ and $8(8 \%)$ could remember their initial correctional facilities because of good correctional officers and for provision of good shelter.

\section{Bad thing about Initial Correctional Facility}

The study further sought to establish whether there was anything bad juvenile recidivists could remember about their initial correctional facility. Out of 100 respondents sampled for the study, 40 (70\%) indicated sexual molestation by fellow offenders as the bad thing they can remember, 38 (38\%) indicated corporal punishment, $18(18 \%)$ indicated bad beddings, while $4(4 \%)$ indicated stealing by correctional officers. This was interpreted to mean that most of the respondents had negative perception about their initial correction facilities because of negative experiences encountered.

\section{Main Mode of Rehabilitation used in Correctional Facilities}

The study sought to establish the main mode of rehabilitation used by correctional officers in dealing with delinquency in respondents. Out of 100 respondents sampled in the study, $70(70 \%)$ indicated that the main mode of rehabilitation used by correctional officers was punishment. Only $30(30 \%)$ of the respondents indicated counseling as the main mode of rehabilitation used to rehabilitate offenders. This was interpreted to mean that 
despite the recognition by authorities in literature reviewed that punishment hardens offenders in criminality, it was found to be the main mode of rehabilitation used by majority of correctional officers. This finding that majority of correctional officers prefer using punishment as mode of rehabilitation over counseling agreed with findings by Mukozi (2010) that most correctional officers in Kampala City, Uganda also preferred use of punishment to rehabilitated juvenile recidivists over counseling.

\section{Capacity of the Correctional Institutions}

The study sought to establish the capacity of correctional institutions. The study confirmed from the correctional officers that, Wamumu rehabilitation school had a capacity of 200 juvenile recidivists while Kirigiti rehabilitation school had a capacity of 120 juvenile recidivists. Furthermore, it was established that Wamumu School had a population of 280 juvenile recidivists out of which 200 (71\%) were recidivists; while Kirigiti had a population of 154 juvenile recidivists out of which $133(84 \%)$ were recidivists. This was interpreted that the correctional facilities were congested and first time offenders were mixed with recidivists.

Highest Level of Education Reached by Correctional Officers

The study sought to examine the highest level of education reached by correctional officers.

Table 5: Correctional Officer's Highest Level of Education

\begin{tabular}{lcc}
\hline Educational Level & $(\mathbf{F )}$ & $(\mathbf{\% )}$ \\
\hline Primary level & 6 & 30 \\
Secondary Level & 6 & 30 \\
Tertiary & 4 & 20 \\
University & 4 & 20 \\
\hline Total & $\mathbf{2 0}$ & $\mathbf{1 0 0}$ \\
\hline
\end{tabular}

The study revealed that majority of the correctional officers did not go beyond secondary education. As shown in table 4.27, out of the 20 correctional officers sampled in the study, majority $16(80 \%)$ indicated that they never went beyond secondary level of education, as 6 (305) of them indicated primary level to be their highest level of education as it was for 6(305) who indicated their highest level of education to be secondary level. The total number of correctional officers who had tertiary and university level of education comprised of only $4(20 \%)$ representation out of 20 correctional officers. Because level of education dictates professionalism of an officer, this finding can be interpreted to mean that only $20 \%$ of the correctional officers had relevant skills to deal with delinquency in respondents.

\section{Staffing in Correctional Facility}

The study sought to establish whether the correctional institutions had trained correctional officers with skills to deal with delinquency in juvenile recidivists. $15(75 \%)$ of the correctional officers sampled in the study indicated that correctional officers did not have the skills to deal with delinquency in juvenile recidivists while only 5 $(25 \%)$ indicated that correctional officers had relevant skills to rehabilitate offenders. All the correctional officers indicated that correctional institutions do not have adequate number of correctional officers to deal with needs of the committed children. This was interpreted to mean that although correctional institutions have many officers only a few are able to attend to the needs of offenders. The correctional officers that correctional facilities seriously needs included teachers, medical officers, children officers, child counselors and spiritual leaders. Participants in two Focused Group Discussions reported that correctional facilities in the study lacked key professionals that would be able to deal with delinquency in juveniles. The Focused Group Discussions revealed that correctional facilities lacked trained officers such as teachers, medical officers, child counselors, spiritual leaders, and adequate tutors. The lack of key trained workers was noted by participants . These findings that correctional facilities lacked key correctional professionals were collaborated by findings of Ndirangu (2008) that correctional facilities in Nairobi, Kenya lacked correctional officers in education, counseling, medical and spiritual nourishment areas.

\section{Rehabilitation Programmes in Rehabilitation Schools}

The study sought to establish from correctional officers whether correctional facilities had adequate rehabilitation programmes to deal with individual needs of each juvenile recidivist committed in their facilities to ensure that they reform.

\section{Availability of adequate Rehabilitation Programmes}

The study sought to establish whether rehabilitation institutions had programmes for rehabilitation of juvenile recidivists committed in them. All correctional officers sampled indicated that rehabilitation schools did not have adequate rehabilitation programmes to deal with all needs of offenders committed in them. In two Focused Group Discussions conducted, the participants concluded that correctional facilities lacked key rehabilitation 
programmes. The main rehabilitation programmes that participants noted to be lacking included educational facilities, health facilities, guidance and counseling services, spiritual services, vocational training facilities and adequate boarding facilities.

Main Rehabilitation Programmes in Correctional Facility

The study sought to establish the main rehabilitation programmes that were available in correctional facilities in the study in which juvenile recidivists were currently committed.

Table 6: Rehabilitation Programmes in Rehabilitation Schools

\begin{tabular}{lcc}
\hline Rehabilitation Programme & \multicolumn{1}{c}{ Correctional Officers } \\
\cline { 2 - 3 } & $(\mathbf{F})$ & $\mathbf{( \% )}$ \\
\hline 8.4.4 Curriculum & 4 & 20 \\
Vocational training & 2 & 10 \\
Guidance and counseling & 1 & 5 \\
Spiritual care & 1 & 5 \\
Sporting and recreation & 12 & 60 \\
\hline Total & $\mathbf{2 0}$ & $\mathbf{1 0 0}$ \\
\hline
\end{tabular}

As shown in table 4.28, out of 20 correctional officers sampled in the study, $6(30 \%)$ indicated that the main rehabilitation programme used in correctional facilities to rehabilitate juvenile recidivists was sports and recreational activities, 4 (20\%) 8.4 .4 curriculum, 2 (10\%) vocational training, while 1 (5\%) indicated that guidance and counseling and; and spiritual guidance each were used. All $100(100 \%)$ of correctional officers indicated that correctional facilities lacked multiplicity of rehabilitation programmes to deal with delinquency in each offender. This was interpreted to mean that correctional facilities emphasized use of sports and recreation due to lack of other market oriented need based programmes.

\section{Main Rehabilitation Facilities in Correctional Institutions}

The study sought to establish whether correctional institutions had adequate rehabilitation facilities. Out of 20 correctional officers, overwhelming majority $11(55 \%)$ indicated correctional institutions lack adequate rehabilitation facilities, compared to only $9(45 \%)$ who indicated that correctional facilities were available. Out of 11 correctional officers who indicated that correctional institutions lacked adequate facilities, $6(54.55 \%)$ indicated that vocational facilities were not available, $3(27.27 \%)$ indicated that education and health facilities were not available, while $2(18.18 \%)$ indicated that boarding facilities were not available. This was interpreted to mean that correctional institutions lacked major facilities that could make rehabilitation environment conducive for rehabilitation process of offenders. This could also mean that lack of main rehabilitation facilities meant lack of key rehabilitation programmes that depend on these facilities therefore making institutional rehabilitation of juvenile recidivists an exercise in futility.

\section{Challenges facing Correctional Facilities}

The study sought to establish the main challenges that were faced by correctional facilities in Kiambu and Kirinyaga counties. In two Focused Group Discussions conducted, the participants reported that inadequate of rehabilitation programmes that would deal with delinquency in juvenile recidivists as the main challenge. Other challenges facing rehabilitation facilities as agreed by participants in the Focused Group Discussions were inadequate funds, overdependence on donations, inadequate number of trained officers, lack of facilities and congestion. This was interpreted to mean that correctional facilities are not prepared to rehabilitate juvenile recidivists because they were faced with many challenges. The two managers of selected rehabilitation schools reported that their schools were faced with many challenges mainly lack of programmes, facilities, trained officers, inadequate funds and juvenile recidivists escaping. The manager of Wamumu rehabilitation school further noted dealing with the problems of sexual molestation of offenders by other offenders and stealing by servants was a major challenge facing the institution. The study found out that experience of negative behaviour by juvenile recidivists while in correctional facility had the highest $(100 \%)$ influence on their recidivism.

The experience of negative behaviours such as homosexuality/ lesbianism, stealing by servant, sexual molestation of respondents by correctional officers and assault of respondents had great negative impact the rehabilitation process of respondents. On the other part, the study found out that lack of correctional facilities had the least (55\%) influence on recidivism among juvenile recidivists in Kiambu and Kirinyaga counties. This also meant that combination of experience of negative behaviour and traumatic experiences from home background resulting from loss of parents, divorce and separation; drug and alcohol use had the greatest negative impact in the live of respondents which went unattended to.

\section{Conclusions}

The objective of the study was examining the influence of correctional facility environment on juvenile 
recidivism. The key finding was that experience of negative behaviour by juvenile recidivists while in correctional facility had the highest contribution on recidivism among respondents in Kiambu and Kirinyaga counties of Kenya than any other factor correctional facility environment. It was therefore concluded that experience of negative behaviour by juvenile recidivists while in correctional facility was the main factor in correctional facility environment that highly contributed to juvenile recidivism in Kiambu and Kirinyaga counties of Kenya.

\section{Recommendations}

The key finding was that experience of negative behaviour by juvenile recidivists while in correctional facility had the highest contribution on recidivism among respondents in Kiambu and Kirinyaga counties of Kenya than any other factor correctional facility environment. It was therefore concluded that experience of negative behaviour by juvenile recidivism while in correctional facility was the main factor in correctional facility environment that had the most contribution to juvenile recidivism in Kiambu and Kirinyaga counties of Kenya.The study therefore recommended that there is need for development of complaints procedures in the correctional facilities which shall ensure that children are able to communicate to the relevant people when something is wrong and also to ensure that appropriate action is taken. Further provision of psychosocial support especially counseling services should be enhanced and given to child offenders who undergo untold suffering then they should be transferred to a place of safety.

\section{REFERENCES}

Adler, F., Muller, G.O. \& Laufer, W.S. (1996). Criminal Justice: The Core. New York. McGraw- Hill, Inc Ackoff, R. (1961). The Design of Social Research. Chicago. University of Chicago Press

Agnew, R. 1992. "Foundations of a General Strain Theory of Crime and Delinquency". Criminology, vol. 30 no. pp. 47-87

Ahuja R. (2001). Research Methods. Jaipur. Rawat Publications

Benda, B. B. (2001). "Factors that Discriminate Between Recidivists, Parole Violators, and No recidivists in a 3Year Follow-Up of Boot Camp Graduates". International Journal of Offender Therapy and Comparative Criminology vol. 45, no. 6, pp.711- 729

Cernkovich, Stephen A. \& Peggy C. Giordano (1992). "School Bonding, Race, and Delinquency". Criminology vol. 30, no. 2, pp. 261-291.

Champion, D. J. (1998). Corrections in the United States: A Contemporary Perspective. NJ: Prentice Hall, Upper Saddle River.

Child Rights Legal Aid (2004). Street Children and Juvenile Justice in Kenya. Nairobi. Unpublished

Ching'andu, A. N. P; \& Welty, M. J. (2008), A Case Study of Hope Worldwide South Africa OVC Programme. Johannesburg. Unpublished

Deborah, H. (2001). Juvenile Delinquency. New York McGraw- Hill, Inc

Delamont, S. (2003). Realizing Qualitative Research. Chicago. Chicago University Press

Dennis, E. ( 1960). The Essentials of Factor Analysis. Rinchart and Wistern

Department of Children Services (2012). Department of Children's Services Annual Report 2011-2012. Nairobi. Government Printer

Department of Children Services (2011). Guideline for Child Participation Manual. Nairobi. Government Printer

Department of Children Services (2007). Manual for Area Advisory Councils. Nairobi. Government printer

Eielson, S. (2007). Communication Slang among Juvenile recidivists in Kingston, Jamaica. International Journal of Criminology. Vol 14

Epstein, N. B., Lawrence M. B., and Duane S. B. (1983). “The McMaster Family Assessment Device”. Journal of Marital and Family Therapy vol. 9, no. 2, pp.171- 180.

Gay, R. (1981). Educational Research Competencies for Analysis and Application. Upper Saddle. Prentice Hall

Glueck, S. \& Eleanor T. G. (1950). Unraveling Juvenile Delinquency, N.Y. Commonwealth Fund

Gordon, D. A., Karen G., and Jack A. (1995). "The Effect of Functional Family Therapy for Delinquents on Adult Criminal Behavior”. Journal for Criminal Justice and Behavior vol. 22, no. 1, pp. 60-73.

Gottfredson, D. M. and Michael, C. (Eds.) (1987). Prediction and Classification: Criminal Justice Decision Making. Chicago: University of Chicago Press.

Haapanen, R. A. (1990). "Selective Incapacitation and the Serious Offender: A Longitudinal Study of Criminal Career Patterns". Research in Criminology Series. NY: Springer-Verlag.

Hagan, F. E. (2003). Research Methods in Criminology and Criminal Justice Allan \& Bacon, MA: Boston

Hirschi, T. (1969). Delinquency. Berkeley, CA: University of California Press

Howell, J. C. (1995). “Gangs and Youth Violence: Recent Research”. In Howell, James C., Barry Krisberg, J. David Hawkins, and John J. Wilson (Eds.). A Sourcebook: Serious, Violent, \& Chronic Juvenile Offenders, 
(pp. 261-274). Thousand Oaks, CA: Sage Publications, Inc.

Human Rights Watch (1997). Juvenile Injustice: Police Abuse and Destruction of Street Children in Kenya. New York. Human Rights Watch.

JIKA (2009). Child Protection Manual: Minimum Standards. Nairobi. Unpublished

Kumar, R. (2005). Research Methodology. A step by Step Guide for Beginners (2 ${ }^{\text {nd }}$ Ed) Nairobi. Sage Publications Ltd.

Laub, J. H., Daniel S. N., and Robert J. S. (1998). "Trajectories of Change in Criminal Offending: Good Marriages and the Desistance Process". American Sociological Review, 63:225-238.

Lavera L.W. (2002). Rehabilitation Process of Juvenile Delinquents in Kenyan Approved Schools. PhD Thesis. Department of Educational Psychology, Egerton University. Unpublished

MaCoy, M. L., David L. R., Patricia H., Roy C., \& Daniel J. L. (2004). “Jail Linkage Assertive Community Treatment Services for Individuals With Mental Illness”. Psychiatric Rehabilitation Journal vol. 27, no. 3, winter, pp. 243-250.

Malakuteko M. W. (2010). Effectiveness of Juvenile Correctional Facilities in Rehabilitation of Juvenile Delinquents in Zambia. M.A Thesis. University of Kwazulu Natal. Unpublished

Malesi, L.W.D. (2006). Juvenile Delinquency: Rehabilitating our Adolescents. Johannesburg. Lowland Publishers

Mbuba, J.M. (2004), Juvenile Recidivism: An Analysis of Race and other Socio- Demographic Predictors within three Intervention Modalities in the State of Louisiana. Louisiana State University. PhD Thesis. International Journal of Criminology

McBride, D. C. and Clyde, B. (1997). "Racial Disparities in Official Assessments of Juvenile Offenders: Attribution Stereotypes as Mediating Mechanisms". American Sociological Review vol. 63, pp. 554-570.

McMurray, M. (1996). "Alcohol, Drugs and Criminal Behavior". In Hollin, Clive R. (Ed.). Working With Offenders: Psychological Research in Offender Rehabilitation, (pp. 211-242). NY: John Wiley \& Sons.

Miner, M. H. (2002). "Factors Associated With Recidivism in Juveniles: An Analysis of Serious Juvenile Sex Offenders". Journal of Research in Crime and Delinquency vol. 39, no. 4, November, pp. 421-436.

Morrison P. ( 2010). Drug and Alcohol use by Young Offenders in the State of Nevada, United States. M.A Thesis University of Colorado. Unpublished

Mpurula, W, (2006). Influence of Institutional Rehabilitation of Child Offenders in Kigali Rwanda. Kigali. United Press of Rwanda

Mugambi, A. (2005). Functions of Children's Department. In a report on Workshop on the Rights of the Kenyan Child. Nairobi. Unpublished.

Mugenda, S.O \& Mugenda, A. G. (2003). Research Methods: Quantitative and Qualitative Approaches. Nairobi: Acts Press.

Nagin, D. S. and Raymond P. (1994). "Personal Capital and Social Control: The Deterrence Implications of a Theory of Individual Difference in Criminal Offending”. Criminology vol. 32, no. 4 pp. 581-606.

Ndirangu L.N. (2008). Rehabilitation of Disadvantaged Children in Nairobi: A comparative Study of Selected Rehabilitation Homes in Nairobi. MA Thesis, Department of Sociology, University of Nairobi.

Njuguna D.W. (2007). Rehabilitation of Juvenile Delinquents: A study of Kabete Approved School, Kenya. Diploma in Criminology. University of Nairobi. Nairobi. Unpublished

Nyamato, R.K. (2006): The Effectiveness of Boarstal Institutions in Rehabilitating Youthful Offenders: A case study of Shimo la Tewa Boarstal Institution. B.A Dissertation, Catholic University of Eastern Africa. Mombasa. Unpublished

Odegwu, O. (2008). Challenges Facing Juvenile recidivists in Juvenile Justice System in Lagos. M.A Thesis. University of Abidjan. Unpublished

Ogbonor, O. (2006). Juvenile Recidivism: Different Perspectives. Lagos. University of Lagos Press.

Okoth, P. G. (2012). Research as a Cornerstone of Quality Assurance in University Education with Specific Reference to Uganda Martys. University Journal of Social Science and Sustainable Development. Vol.5: $37: 57$

Paternoster, R. and Alex P. (1995). "Reconceptualizing Deterrence: An Empirical Test of Personal and Vicarious Experiences". Journal of Research in Crime and Delinquency vol. 32, no. 3, pp. 251-286.

Peterson S. (2009). Reforming Juvenile Justice System in Columbia. Study of Juvenile Correctional facilities in Columbia. PhD Dissertation. Unpublished.

Puzzanchera, C. M. (2003). "Delinquency Cases Waived to Criminal Court, 1990-1999". Office of Juvenile Justice and Delinquency Prevention, Office of Justice Programs, U.S. Department of Justice, Fact Sheet, September 2003 \# 04.

Sabol, J., William P. Adams, B. P., and Yan, Y. (2000). “Offenders Returning to Federal Prison, 1986-97”. Bureau of Justice Statistics, Special Report (NCJ, 182991). Washington, DC: U.S. Department of Justice, Office of Justice Programs, National Institute of Justice. 
Sebastian, B \& Byenkya, T. (2008). A Case Study of AMREF South Africa. Sekhukhune and Umkhanyakude OVC Programme. Khulisa Management Services. Johannesburg, South Africa.

Thornberry, T. P., David, H., and Rolf, L. (1995). "The Prevention of Serious Delinquency and Violence: Implications From the Program of Research on the Causes and Correlates of Delinquency". In Howell, James C., Barry Krisberg, J. David Hawkins, and John J. Wilson (Eds.). A Sourcebook: Serious, Violent, \& Chronic Juvenile Offenders, (pp. 213-237). Thousand Oaks, CA: Sage Publications, Inc.

Thurman, T.R., Hoffman, A. Chatterji, M. \& Brown, L ( 2007. Causes of offending among Orphans and Vulnerable Children in Kilifi. Unpublished

Wakanyua, S.N. (2005). Rehabilitation of Juvenile Delinquents: A survey of Approve Schools in Kenya. M.A Thesis in Sociology, University of Nairobi. Unpublished

Wanyoike, F. M. (1989). Juvenile Delinquency and the role of physical Environment in Rehabilitation Programme. Bachelor of Architecture Thesis. University of Nairobi. Nairobi. Unpublished

Warr, M. (1993). "Parents, Peers, and Delinquency". Social Forces, vol. 72, No. 1, September, pp. $247-264$.

Warr, M. and Mark, S. (1991). "The Influence of Delinquent Peers: What They Think or What They Do?" Criminology vol. 29, No. 4, pp. 851-867.

Winter, Q. \& Ian, T. (2000). Towards a Theorized Understanding of Family Life and Social Capital. Melbourne, Australia: Australian Institute of Family Studies.

Wright, B. R.; Avshalom C., Terrie E.; Moffitt S., and Phil A. S. (1999). "Low Self-Control, Social Bonds, and Crime: Social Causation, Social Selection, or Both?” Criminology, vol. 37, no. 3, pp. 479-514. 